\title{
HEAT TRANSFER BY NATURAL CONVECTION THROUGH V-CORRUGATED PLATES
}

\author{
Mohammad Ali and M. Hasanuzzaman \\ Department of Mechanical Engineering \\ Bangladesh University of Engineering and Technology \\ Dhaka-1000, Bangladesh
}

\begin{abstract}
An experimental investigation is performed on natural convection heat transfer through a square enclosure of $V$ corrugated vertical plates. The objective of this investigation is to study the variation of heat transfer rate through the square enclosure with the variation of both hot and cold plate temperatures. Hot plate temperature is varied by heat input. To vary cold plate temperature two parameters are considered: one is mass flow rate of water used to remove heat from cold plate and the other is the inlet temperature of water. Air is the media to transfer heat from the hot V-corrugated plate to cold $V$-corrugated plate. The result shows that the increase of mass flow rate increases the heat transfer rate and the decrease of water inlet temperature increases the heat transfer rate.
\end{abstract}

\section{INTRODUCTION}

Natural convection is an important mode of heat transfer. The existence of natural convection heat transfer between horizontal plates heated from below was first referred by Thomson ${ }^{1}$ in 1882 noting the presence of cellular patterns in soapy water whose mean temperature was greater than the ambient. In 1900, Benard ${ }^{2}$ published photographs taken with a beam of parallel light that has passed through a layer of paraffin oil whose thickness was small compared with its diameter and which was heated from below. Those photographs clearly indicated the presence of a hexagonal cellular convection pattern. Natural convection is observed because of the motion of the fluid due to density change arising from heating process. The movement of the fluid in natural convection results from the buoyancy forces imposed on the fluid when its density in the proximity of the heat transfer surface is decreased because of thermal expansion of the fluid in a non-uniform temperature distribution. Convection heat transfer is dependent on the movement of the fluid and the shape of the heat transfer surfaces influences the development of the flow of fluid. A significant number of investigations have been carried out on heat transfer across V-corrugated and other configured surfaces. Chinnappa ${ }^{3}$ carried out an experimental investigation on natural convection heat transfer from a horizontal lower hot $\mathrm{V}$-corrugated plate to an upper cold flat plate. The author took data for a range of Grashof number from $10^{4}$ to $10^{6}$. The author noticed a change in the flow pattern at Grashaf number, $\mathrm{Gr}=8 \times 10^{4}$, which he concluded as a transition point from laminar to turbulent flow. Randall et al. ${ }^{4}$ studied local and average heat transfer coefficients for natural convection between a V-corrugated plate $\left(60^{\circ} \mathrm{V}\right.$-angle) and a parallel flat plate to find the temperature distribution in the enclosed air space. The author recommended a correlation in which the heat flux is $10 \%$ higher than that for parallel flat plate. Elsherbiny et al. ${ }^{5}$ investigated free convection heat transfer for air layers bounded by a lower hot V-corrugated plate and upper cold flat plate. A single correlation equation in terms of Nusselt number, Rayleigh number, tilt angle and aspect ratio was developed for the aspect ratio ranging from 1 to 4 and angle of inclination ranging from 0 to 60 degrees. They claimed that the convective heat transfer across air layer bounded by V-corrugated and flat plate was greater than those for parallel flat plates by a maximum of $40 \%$.
Beitelmal et al. $^{6}$ performed an experimental investigation on the effect of surface roughness of a uniform heated plate on the average heat transfer characteristics of an impinging air jet. Temperature and heat transfer were measured for variation of both Reynolds number and jet exit-to-plate spacing. The average Nusselt number for both cases was plotted versus the Reynolds number and their functional correlation was determined. The results indicated an increase of up to $6.0 \%$ of the average Nusselt number due to surface roughness.

Zhong et al. ${ }^{7}$ carried out a finite difference study to determine the effects of variable properties on the temperature and velocity field and the heat transfer in a differentially heated two-dimensional square enclosure. Nayak et al. ${ }^{8}$ considered the problem of free and forced convection in a full-developed laminar steady flow through vertical ducts under the conditions of constant heat flux and uniform peripheral wall temperature. Ozoe et al. ${ }^{9}$ performed a set of experiments for laminar convection in silicone oil and in air along a rectangular channel. The aspect ratios (width/height) of the cross-section of the channel were $1,2,3,4.2,8.4$ and 15.5 and the Rayleigh number was varied from $3 \times 10^{3}$ to $10^{5}$. Sofir Uddin et al. ${ }^{10}$ investigated the natural convection heat transfer and fluid behavior for vertical sinusoidal walls. The result showed that for corrugation frequency $=3$ with different Grashof numbers, the heat flux became lower than that of straight wall and with corresponding Grashof number for corrugation frequency $=1$, the total heat flux became higher than that for the straight one. Dropkin et al. ${ }^{11}$ performed an experimental investigation on natural convection heat transfer in liquid confined by two parallel plates and inclined at various angle with respect to horizontal direction. The range of Rayleigh number covered in the experiment was $5 \times 10^{4}$ to $7 \times 10^{8}$ and Prandtl number was varied from 0.02 to 11560 . Experiments were carried in rectangular and circular containers having copper plates and insulating walls. The liquid used was water, silicon oil and mercury. De Graaf et al. ${ }^{12}$ studied the heat transfer rate for air layers of inclination angle ranging from 0 to 90 degree. The range of Rayleigh number covered was approximately $10^{3}$ to $10^{5}$. However, from the review of published results it can be pointed out that there is no useful data on natural convection heat transfer with Vcorrugated vertical walls, which forms the basis for the motivation of present study. 


\section{EXPERIMENTAL SETUP}

The experimental setup of the investigation is a square enclosure with two V-corrugated vertical plates. One is a hot plate heated by electric heater and the other is a cold plate cooled by water reserved in a tank.

The experimental setup consists of the following assembly:
(a) The hot and cold plates assembly
(b) The heater assembly
(c) The thermocouple assembly
(d) The insulator assembly

\section{The hot and cold plate assembly}

Hot plate as shown in Fig. 1 is made of corrugated mild steel sheet of height $42 \mathrm{~cm}$, width $42 \mathrm{~cm}$ and thickness $2 \mathrm{~mm}$. The corrugation amplitude is fixed at 5 percent of the enclosure height, where the amplitude is defined as a half of the horizontal distance, measured from the left extremity of the left wall to its right extremity and therefore, the amplitude is $2.1 \mathrm{~cm}$. Folding of a plain sheet with angle makes this corrugation. The cold plate is similar to the hot plate and is used to gain heat from hot plate. The assembled configuration formed by hot and cold plates are shown in Fig. 2.

\section{The thermocouple assembly}

There are 18 thermocouple points to measure the temperature of the surfaces of two V-corrugated parallel vertical plates. Nine thermocouple points at different places are used in hot plate as shown in Fig. 3 and the other nine thermocouple points are used in cold plate as shown in Fig. 4. The thermocouples are located at different points so that it can cover the critical positions and can conform uniform heating of plates.

\section{The insulation assembly}

The insulation assembly consists of asbestos cloth, asbestos tape, glass wool and white tape. The whole body of the setup is covered with asbestos cloth.

\section{The heater assembly}

There are two layers of asbestos on the plate to be heated. Nicrome wire of specification 26 is used for the heater. The wire is placed in between the layers of asbestos. The wire makes a loop on the plate in a rectangular manner as shown in Fig. 5 and tape is used to hold the wire on the asbestos. Asbestos cloth can sustain $120^{\circ} \mathrm{C}$. So, the temperature of heater is kept within this range.

\section{Mathematical Modeling}

In this experiment, the V-corrugated plate is heated by electric heater as stated earlier. The equation of the input power can be written as

\section{$P=V \times I \times \cos \theta$}

where, $P$ is input power in watt, $V$ is input voltage in volt and $I$ is input current in ampere. The heat transfer from hot V-Corrugated plate to cold V-Corrugated plate by natural convection can be written as

$$
Q_{\text {hotplate }}=A \times h \times\left(T_{\text {hotplate }}-T_{\text {coldplate }}\right)
$$

where, $A$ is area of hot plate, $\mathrm{m}^{2}$ and $h$ is convection heat transfer coefficient, $\mathrm{W} / \mathrm{m}^{2}$.K. The equation of heat gained by water can be written as

$Q_{\text {water }}=m \times C p \times d T$

Where, $C p$ is specific heat at constant pressure, $T$ is temperature in ${ }^{\circ} \mathrm{C}, d T$ is outlet water temp - inlet water temp in ${ }^{\circ} \mathrm{C}$ and $m$ is mass flow rate of water in $\mathrm{gm} / \mathrm{s}$.

\section{RESULTS AND DISCUSSION}

In this experiment natural convection heat transfer through V-corrugated vertical plates has been investigated. In this investigation, water is used as coolant and air is present in the rectangular box between the two Vcorrugated vertical plates. The rectangular enclosure has adiabatic surroundings. Therefore, it is expected that the heat transfer will occur only through air confined by enclosure.

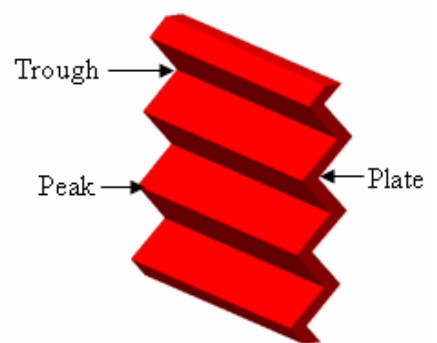

Fig. 1: Hot and cold plate Assembly

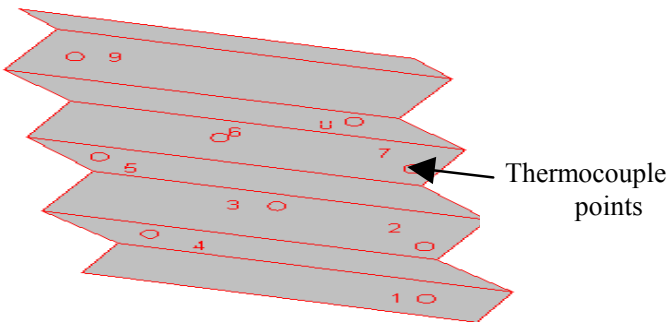

Fig.3 Thermocouple points in hot plate.

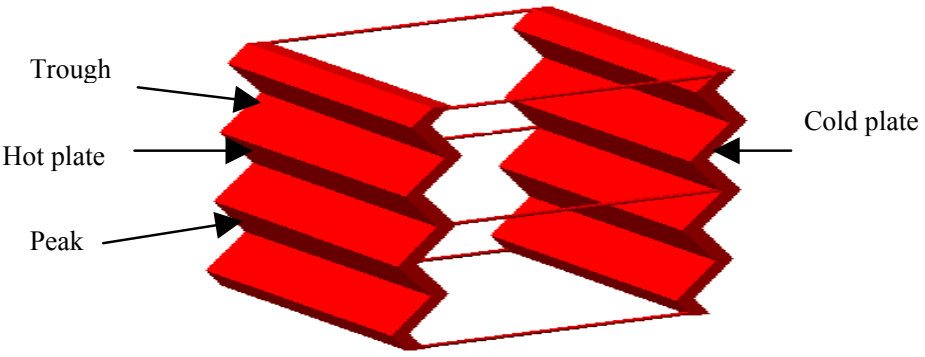

Fig.2: Assembled configuration of V-corrugated plates

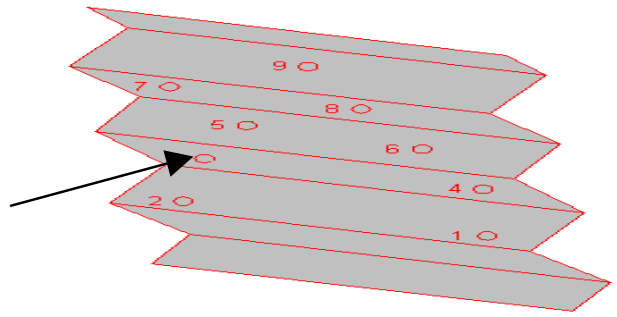

Fig.4 Thermocouple points in cold plate. 


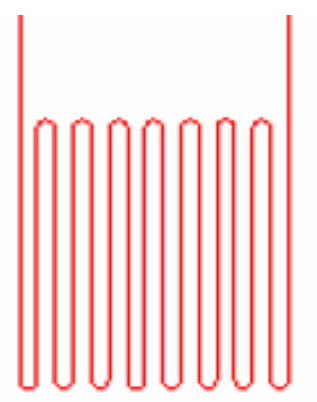

Fig. 5 Nicrome wire loop of heater

Temperature distribution on hot plate

In this investigation, Figs. 6 and 7 show the temperature distribution on the hot plate for different heat inputs to the hot side plate. From these figures, we see that temperature of the plate is almost same at all thermocouple points. Small variation of temperature in several thermocouple points can be observed. Between the plate and heater, asbestos is used. As the plate is corrugated, contact between asbestos and plate surface might be loose or tight. Intimate contact of the "peak" of the corrugated plate with asbestos can be obtained but the fitting of the "trough" of the corrugated plate with asbestos might loose. Along the "trough" there is a possibility to stay an air gap between the surface of the plate and asbestos. Therefore, the temperature of the "peak" of the corrugated plate is greater than that of the "trough" of the plate. However, due to wave of V-corrugation, small variation of temperature in a few points is observed.

\section{Temperature distribution on cold plate}

Figures 8 and 9 show the temperature distribution in the cold plate for different input power. Though the temperature at all points of the plate should be same, small variation can be observed at different thermocouple points.
Water is flowed over the cold plate. During water flow, the "trough" of the corrugation produces low velocity of flowing water, whereas the "peak" of the corrugation produces high velocity of flowing water. Consequently thick boundary layer forms at the "trough" of corrugation. Therefore, temperature at the "trough" of the plate is higher than that at the "peak" of the corrugation. For this reason, little variation of temperature is found among different thermocouple points.

\section{Effect of different variables}

In this study the heat transfer through V-corrugated vertical walls is investigated for the variation of

(i) Mass flow rate of cooling water

(ii) Input heat energy, and

(iii) Inlet water temperature

\section{(i) Effect of mass flow rate of cooling water}

Figure 10 (input power 70 watt) and Fig. 11 (input power 110 watt) show the change of heat transfer rate with respect to mass flow rate of cooling water. Both of the figures show that if mass flow rate of water increases, heat transfer rate increases. This is quite natural because for increasing flow rate, the temperature difference between water and confined wall is higher and eventually heat transfer increases. However for low input power as shown in Fig. 10 the slope of the curve is higher for low mass flow rate of water and for high mass flow rate of water the slope of the curve is lower. On the other hand, for high input power as shown in Fig. 11 the slope of the curve is constant which means that the increment of heat transfer is same for different mass flow rates of cooling water used in this investigation. It can be predicted that if mass flow rate of water is further increased for high input power (110 watt), the trend of heat transfer increment might change as can be seen in Fig. 10.

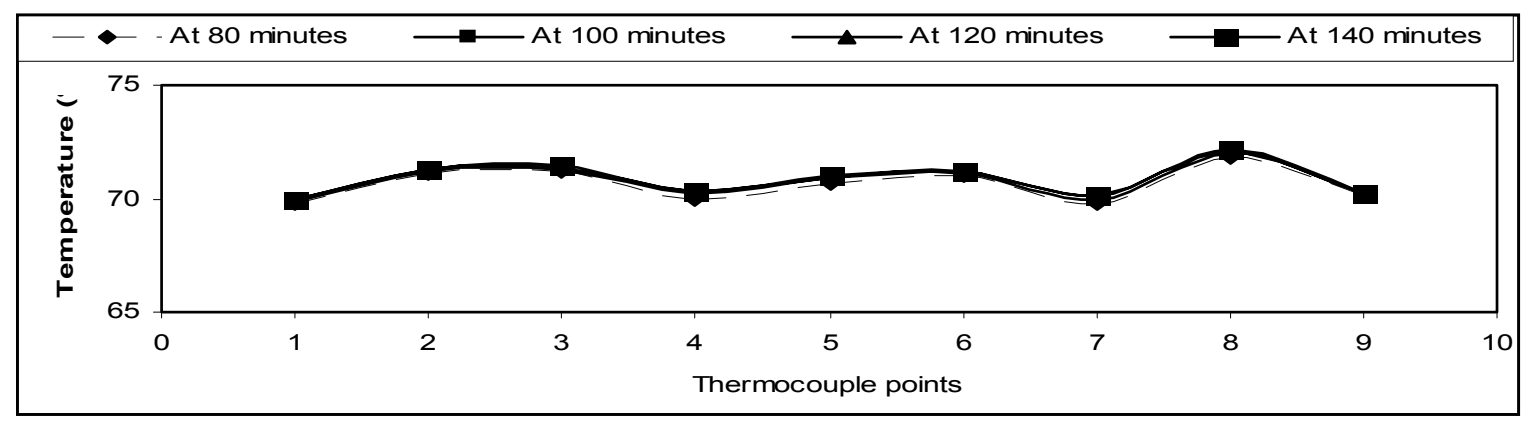

Fig. 6 Temperature distribution in hot V-corrugated plate (Input power 70 watt)

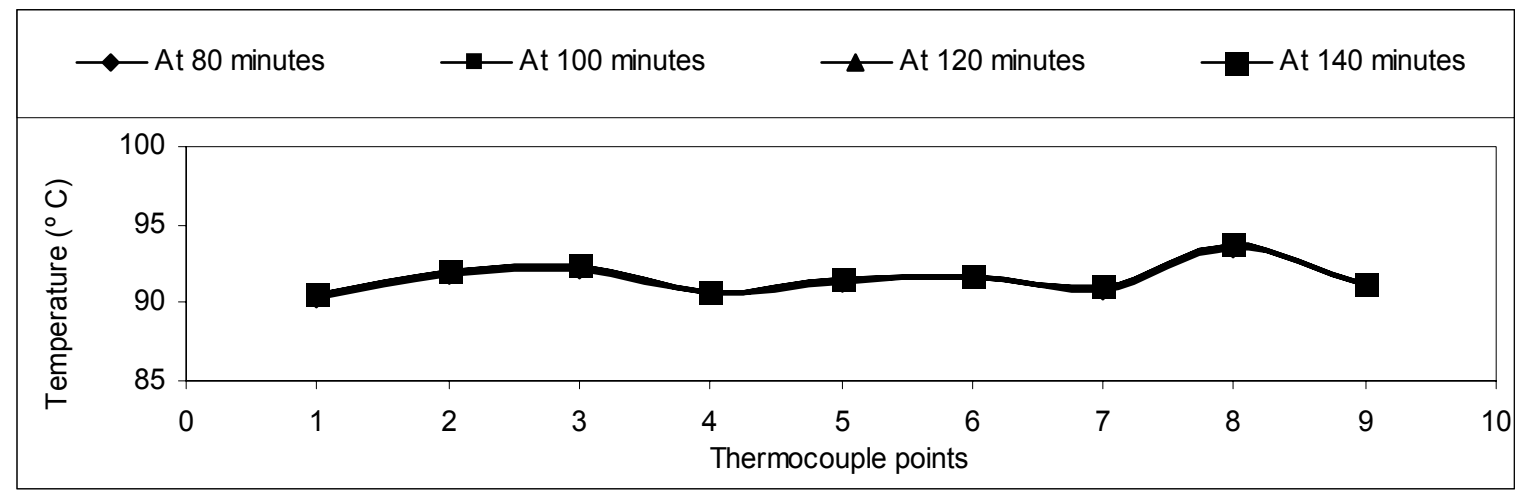

Fig. 7 Temperature distribution in hot V-corrugated plate (Input power 110 watt)

Journal of Mechanical Engineering, vol. ME36, Dec. 2006

Transaction of the Mech. Eng. Div., The Institution of Engineers, Bangladesh. 


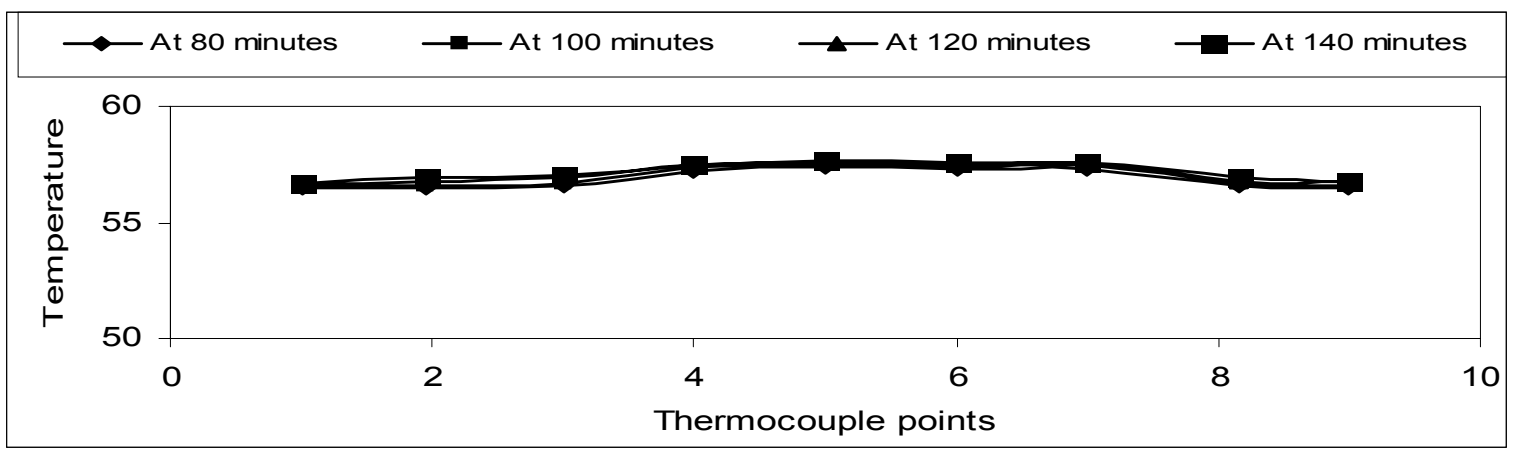

Fig. 8 Temperature distribution in cold V-corrugated plate (Input power 70 watt)

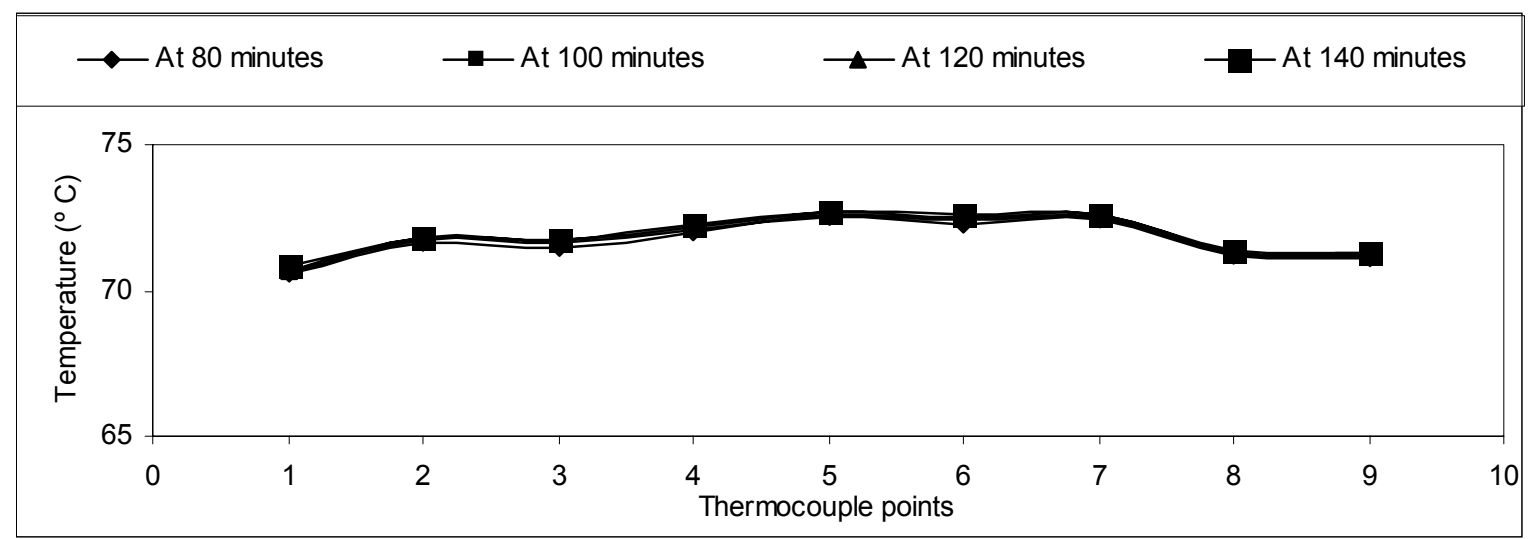

Fig. 9 Temperature distribution in cold V-corrugated plate (Input power 110 watt)

\section{(ii) Effect of input energy}

Figures 10 and 11 show the change of heat transfer rate with respect to input power. If input power increases, heat transfer rate also increases caused by the higher temperature difference. By the slope of the curve it can be understood that for low mass flow rate of cooling water, the increment of heat transfer is higher for low input power but for high mass flow rate of water the increment of heat transfer decreases which is caused by the short residence time of water in the chamber. By comparing the slopes of the curves in Figs. 10 and 11, it can be observed that for higher input energy the slope of curve is low for low flow rate of cooling water and vice-versa. This trend is caused by insufficient mass flow rate of cooling water for high input power.

\section{(iii) Effect of inlet water temperature}

Heat transfer rate depends on the inlet water temperature. Figure 10 shows that for input power of 70 watt, heat transfer rate increases with decreasing of water inlet temperature. For a constant mass flow rate of water, heat transfer rate is greater at inlet water temperature $17.3^{\circ} \mathrm{C}$ than that at inlet water temperature $27.2^{\circ} \mathrm{C}$ which is caused by higher temperature difference of cooling water and cold wall. The curve in Fig. 11 also shows same trend on heat transfer. From the above information, we can see that the increasing of both input power and mass flow rate of cooling water increases heat transfer rate. Heat transfer rate increases with decreasing of inlet cooling water temperature.

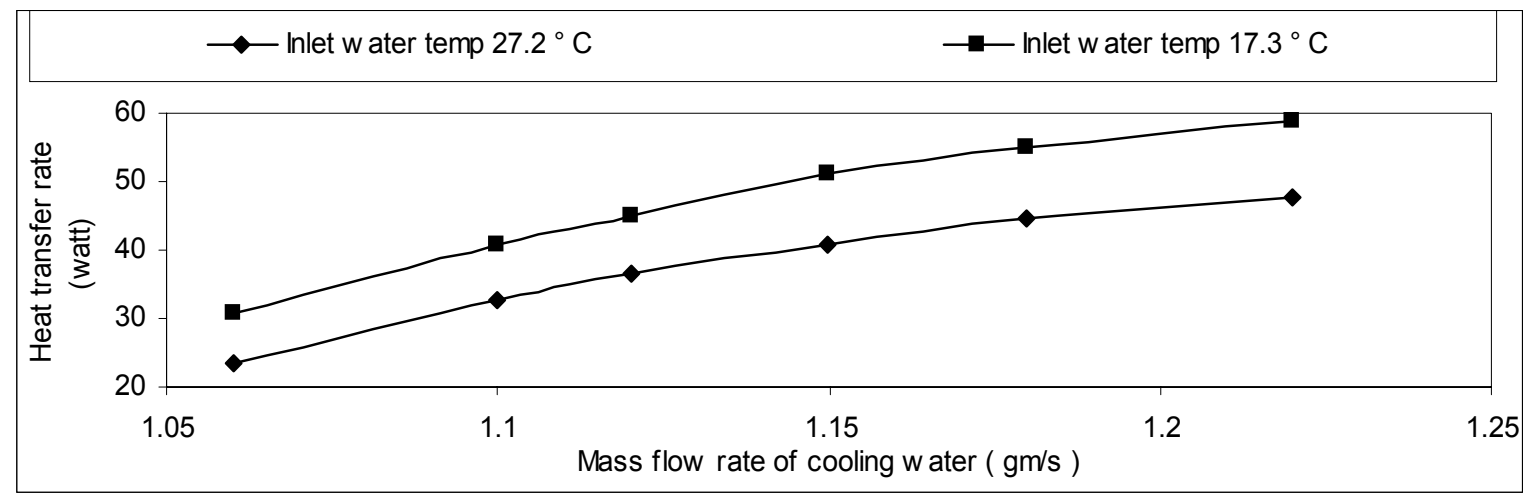

Fig. 10 Variation of heat transfer rate with mass flow rate of water (Input power 70 watt)

Journal of Mechanical Engineering, vol. ME36, Dec. 2006

Transaction of the Mech. Eng. Div., The Institution of Engineers, Bangladesh. 


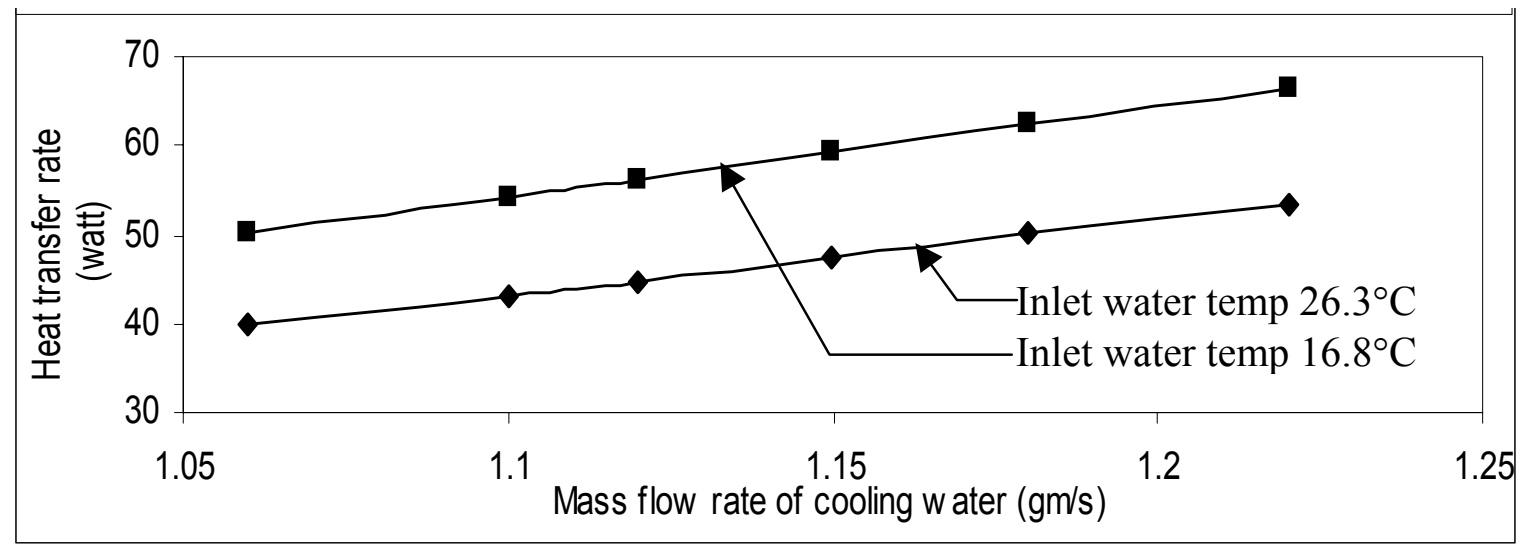

Fig. 11 Variation of heat transfer rate with mass flow rate of water (Input power 110 watt)

\section{CONCLUSION}

Natural convection heat transfer through an enclosure with V-corrugated vertical walls has been analyzed and discussed. Heat is transferred from hot plate to cold plate through air by natural convection and from cold plate heat is removed by cooling water. Though the temperature should be uniform at all points of hot and cold plates, slightly higher temperature can be observed at the peaks. It is found that heat transfer rate increases with the decrease of inlet water temperature. Heat transfer rate increases with the increase of input power and mass flow rate of water. For low input power, the increment of heat transfer is high for low mass flow rate of water but high mass flow rate of cooling water causes low increment of heat flux. On the other hand, for high input power constant increment of heat transfer can be observed with the increase of mass flow rate of cooling water.

\section{REFERENCES}

1. Thomson, J.J., "Proc. Glasgow Phil. Soc.", Vol.,13,1882, pp. 464.

2. Benard, H., "Rev. Gen. Sci. Pures Appl.”, Vol.11, 1900, pp.1261-1271.

3. Chinnappa, J.C.V., "Free Convection in Air between a V-Corrugated Plate and Flat Plate", Int. J. Heat and Mass Transfer, Vol.13, 1970, pp.117-123.

4. Randall, R.K., "Interferometer Investigation of Convection in Salt-Flat Plate and V- Corrugated Solar Collectors", J. Heat Transfer, Trans ASME, Vol. 101, 1979, pp.120-125.

5. Elsherbiny, S.M., Holland, K.G.T., and Daithby, G.D., "Free Convection across Inclined Air Layers with One Surface V-Corrugated", in Heat Transfer Solar Energy Systems, Howell, J.R. and Min, T., (Eds) ASME, New York, 1977.
6. Beitelmal, A. H., Saad, M. A. and Patel, C. D., "Effects of Surface Roughness on the Average Heat Transfer of an Impinging Air Jet," Int. Communications in Heat and Mass Transfer, Vol. 27, No. 1, January 2000, pp. 1-12.

7. Zhong, Z.Y., Young, K.T., and Lioyad, J.R., "Variable Property Effects in Laminar Natural Convection in A Square Enclosure", J. Heat Transfer, Vol.107, 1985, pp.133-146.

8. Nayak, A.L., and Cheny, P., "Finite Elements Analysis of Laminar Convection Heat Transfer in Vertical Ducts with Arbitrary Cross Section", Int. J. Heat and Mass Transfer Vol. 18, 1975, pp.67-71.

9. Ozoe, H., Sayma, H. and Churchill, S.W., "Natural Convection in an Inclined Rectangular Channel at Various Aspect Ratios and Angles: Experimental Measurements." Int. J. Heat and Mass Transfer, Vol. 18, 1975, pp. 1425-1431.

10. Sofir Uddin, M., Al-Azad, S. and Roy, B. D., "Natural Convection Heat Transfer and Fluid Flow in A Square Enclosure with Corrugated Vertical Walls', B. Sc., Engg, Thesis, 1988, BUET.

11. Dropkin, D., and Somercales, E., "Heat Transfer by Natural Convection in Liquids Confined by Two Parallel Plates Which Are Inclined at Various Angles with Respect to Horizontal", J. Heat Transfer Series C, Vol. 87, 1965, pp-84

12. De Graaf, J. G. A., and Vender Held, F. E. M., "The Relation between the Heat Transfer and Convection Phenomena in Enclosed Plain Air Layers." Appl. Sci. Res. A. Vol. 3, 1953, pp 393-409. 